\title{
Effective approaches to improve the psychosocial work environment
}

\author{
Bishal Gyawali \\ Unit of Health Promotion, University of Southern Denmark, Esbjerg, Denmark. \\ Correspondence to: Bishal Gyawali, E-mail: bishalforu@hotmail.com
}

Received August 3, 2014. Accepted August 26, 2014

\section{Abstract}

There has been a growing recognition that the experience of psychosocial hazards at work has detrimental effects on the health and well-being of employees, as well as on the workplace productivity and profits. Issues such as work-related stress, bullying, and stress due to harassment have grown in prominence in recent years in response to a number of factors such as overwork, job insecurity, low levels of job satisfaction, and lack of autonomy. These hazards are highly underestimated in most of the workplaces because of the difficulties involved with their detection and management and eventually represent risks to physical and psychological health. Reducing this huge burden from unhealthy workplaces is a formidable challenge for national governments, health policy makers, and practitioners. The growing burden of psychosocial hazards at workplace has guided to review the literature on the effective approaches to improve psychosocial work environment. It is concluded that adapting the systems and structured approach to psychosocial health risk management will be effective to prevent hazards and manage psychosocial work environment.

KEY WORDS: Psychosocial, health promotion, hazards, risks, prevention

\section{Introduction}

The WHO (World Health Organization) defines health as a state of complete physical, mental and social well-being and not merely an absence of disease or infirmity. ${ }^{[1]} \mathrm{A}$ good health is defined not only by the absence of disease or infirmity but also by the abundance of health-promoting conditions. One of such health-promoting conditions is a psychosocial work environment aimed at influencing the behavior and development of workers at workplace. ${ }^{[2]}$ In other words, the psychosocial environment is related to interpersonal and social interactions and is defined by the set of psychological, cognitive, and behavioral phenomena of work environment that influence behavior, feelings, and thoughts of workers. ${ }^{[3]}$ Today, globalization has added pressures such as high workload to workers to compete with companies across the globe. Such high-pressured work environments produce stressors that exert adverse health effects on workers. Those "stressors," which create new challenges and emerging threats at a workplace, are the "risk factors" or "hazards."

\begin{tabular}{|l|l|}
\hline Website: htp://wnw.jmsph.com & Access this article online \\
\hline DOl: 10.5455/jimsph.2015.0308201426 & \\
\hline
\end{tabular}

Hazards at workplace are related to the way work is designed, organized, and managed such as differences between job content, workload, work schedule and workplace, environment and equipment, control at work as well as different economic and social contexts of work. ${ }^{[2]}$ The International Labor Organization (ILO) defines "psychosocial hazards" as those interactions among organizational conditions and employees' competencies that prove to have a hazardous influence over employees' health through their perceptions and experience ${ }^{[4]}$ It is evident that a poor psychosocial working environment resulting from psychosocial hazards can have an impact on workers' physical health and mental well-being as well as the health of the organization. Such psychosocial impact represents a huge cost for worker's health and productivity and hence, is regarded as important social determinants of global health. ${ }^{[5]}$ These hazards are highly underestimated in most of the workplaces of the world because of the difficulties involved with their detection and management. In addition, there is lack of policies, voluntary actions, and research in organizations that address psychosocial hazards and work-related stress. Reducing this huge burden from unhealthy workplaces is a formidable challenge for national governments, health policy makers, and practitioners.

The growing burden of psychosocial hazards at workplace has guided to review the extent of the psychosocial problems at workplace and opt for an appropriate intervention strategy to manage these hazards. This article at first presents a current snapshot on psychosocial work environment, discusses the burden and health impacts of psychosocial hazards, and 
finally suggests a practical approach to improve the psychosocial environment at workplace.

\section{Extent of the Problem}

According to the ILO Report on Safety at Work, globally, an estimated 2 million people die every year from occupational hazards and work-related stress or injuries. ${ }^{[6]}$ Different studies have indicated that effects of stress on individuals are associated with depression, burnout, musculoskeletal disorders, cardiovascular disease, metabolic syndrome, and diabetes. $^{[4,7,8]}$ The WHO Report of 2010 has mentioned that depression resulting from occupational risks accounts for $8 \%$ of the global burden of disease. ${ }^{[6]}$ The US national co-morbidity survey on labor workforce reported that approximately $3.6 \%$ of workers experienced major depression and $18 \%$ of the workforce experienced some form of mental illness at any point in time. ${ }^{[9]}$ A study from Canada showed that $51 \%$ of employees experienced stress at workplace. ${ }^{[10]}$ Approximately $15 \%-30 \%$ of workers in the UK experienced some form of mental health problems during their working lives. ${ }^{[11]}$ A report showed that approximately $46 \%$ of workers in India experiencing stress had diabetes, $39 \%$ had heart problems, and approximately $49 \%$ had a history of high blood pressure. ${ }^{[9]}$ Likewise, a wide range of unhealthy behaviors such as alcohol and drug abuse, increased cigarette smoking, violence, accident proneness, poor sleep, and obesity have been reported among workers due to exposure to psychosocial hazards. ${ }^{[12]}$ At the organizational level, stress due to work is associated with the consequences such as complaints, grievances, staff turnover, decrease in motivation and satisfaction, fatigue resulting from long hours of work or shift work, and occupational violence, which have negative impacts on product and service quality thereby affecting the economy as well as the reputation of the organization. ${ }^{[2,13]} \mathrm{A}$ study by Noor ${ }^{[14]}$ among marketing executives in Pakistan found workplace stress as an important predictor of staff turnover in organizations. Moreover, a recent report from the ILO mentioned that $40 \%$ of global employee turnover was attributed to stressors at work. ${ }^{[15]}$

The potential hazards or risk factors can arise from two aspects: organization of work and organizational culture in the work environment. ${ }^{[16]}$ The organization of work covers aspects of the way work is designed such as workload, fairness in the distribution of work, clarity of roles and expectations, manner of communication in the organization, psychological fit between the employee's interpersonal and emotional competencies, and opportunities for growth and development. Likewise, the organizational culture is related to the attitude, values, and beliefs that guide workplace behaviors such as trust between managers, workers and management; appreciation and recognition; as well as honesty and transparency. ${ }^{[17]}$ The absence of these factors at workplace may become the source of stress or stressors and can negatively impact on the organizational measures such as absenteeism, productivity, and turnover.
Causes and consequences of increased psychosocial hazards at workplace can be attributed to lack of awareness about the psychosocial hazards and shortage of resources to deal with those hazards. ${ }^{[4]}$ There are not many research studies focused on the individual and organizational intervention to improve psychosocial work environment. At the same time, there is a gap between policy and practice at workplace, and a better understanding of the concept of psychosocial hazards and their associated risks is necessary to control them effectively. ${ }^{[18]}$

\section{Preventing and Managing Psychosocial Hazards}

The burden of many psychosocial hazards can largely be reduced by prevention and management. Protecting workers from psychosocial hazards is very important, indeed very challenging at the same time, and needs an integrated approach at various levels. Various approaches have been proposed so far for preventing and managing hazards at workplace. Conventionally, interventions for workplace hazards used to be focused on individual self-efficacy of workers such as coping and management skill development. ${ }^{[19]}$ However, individual-focused approach without other interventions can only influence individual-level outcomes but not at the organizational level. In a systematic review, Van der Molen et al. ${ }^{[20]}$ emphasized on organization-oriented interventions such as inspections, trainings, and introduction of occupational health services for reducing nonfatal injuries at workplace. Later on, it was found that the approach was of low-quality evidence and was unable to give the complete picture of the management process even though it was aimed at managing psychosocial hazards. There is good evidence available to show that interventions comprising both organizational and individual approaches can modify risk factors as well as reduce enduring health effects. ${ }^{[12]}$ For instance, LaMontagne et al. ${ }^{[21]}$ in a review pointed out the systems approach integrating primary, secondary, and tertiary intervention was effective in preventing and controlling job stress at workplace. Cox and Griffiths ${ }^{[22]}$ further affirmed that framework incorporating both the systems and structured approaches was confirmed to be a successful strategy in managing risks at work.

It is believed that adapting the systems and structured approach to psychosocial health risk management will be effective to prevent hazards and manage psychosocial work environment. The effective risk management process, however, requires commitment from managers, employees, and a wide range of stakeholders. Moreover, Morag and $\mathrm{Luria}^{[23]}$ in a systematic review on a framework for performing workplace hazard and risk analysis highlighted that managerial involvement and participation of all workers are keys to successful implementation of the risk analysis. The concerned authorities, therefore, need to ensure that the approach is fully implemented in their areas of control and also that their workers are consulted for identifying hazard, assessing risk, and controlling them.

The systematic and structured approach to risk management that is aimed at improving psychosocial work environment can best be described in the following ways [Figure 1]. 

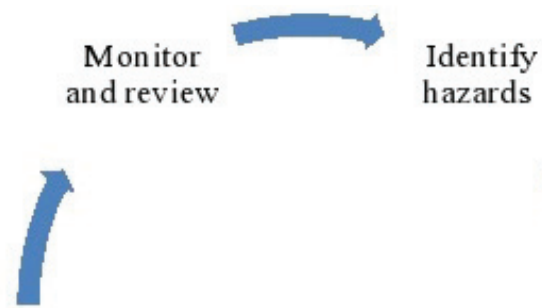

In formation and feeback

Implement

control

measures

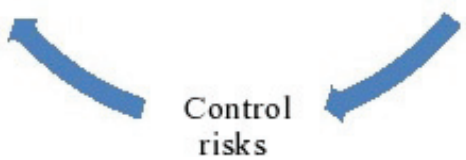

Information and feeback

Figure 1: Risk management cycle

\section{Identify Hazards}

The first step in the risk management process is to identify the potential sources of harm to employee health and wellbeing at workplace. The work-related hazards such as stress, job control, and workload can be identified from various sources such statistics and past records, incidents and accidents, examining workplaces, brain storming, reports from health and safety representatives, evaluating levels of productivity, absenteeism rates, employee turnover, customer feedbacks, and from different data trends.

\section{Assess the Risk}

Having identified sources of potential harm to psychological health and well-being in an organization, the next step is to systematically assess the risk to prioritize areas or issues in action. It involves a thorough assessment of what could harm people in the workplace, allowing employers to weigh up whether they have taken enough precautions or need to do more to prevent harm. The control option has to be implemented immediately if the level of risk assessed is extreme. ${ }^{[24]}$ The results of an appropriate and thorough risk assessment will help to find out suitable intervention measures to be taken to protect the health of workers. The assessment can be made by conducting surveys, through observation, or focus group discussions. One of the examples can be an assessment of the likelihood and consequences of injury or illness that may result from exposure to work-related stressors. However, at present, context validity of using the risk assessment tools at workplace has become an issue because of difficulty in using risk assessment tools, which is believed to create problems while assessing impacts. ${ }^{[25]}$

\section{Control Risks}

The third step is to decide on measures to control the risk. The most effective control measure to get rid of the hazard completely is to eliminate the hazard. If the hazard cannot be eliminated completely, different control options should be used to prevent or minimize exposure to risk such as removing the hazard or substituting less hazardous equipment; redesigning of equipment at workplace and processes that reduce the exposure source; isolating hazardous tools; adapting different administrative controls such as timing of work, policies, and work practices (training, equipment maintenance, and personal hygiene practices); or using personal protective equipment. ${ }^{[24]}$

\section{Implement Control Measures}

After the assessment of potential risk, the most appropriate control measures that are reasonably practical in the circumstances need to be selected and implemented. The intervention has to be carried out using systems approach that integrates primary, secondary, and tertiary interventions, which have been described next. ${ }^{[21]}$ Some hazard-specific strategies for dealing with occupational psychosocial hazards are mentioned in Table 1.

Primary Intervention. Primary intervention methods are proactive actions aimed at preventing illness among individuals by reducing stress exposure. ${ }^{[21]}$ Primary intervention seeks to combat work-related stress by changing elements in the way work is organized and managed, and are associated with the organizational culture. Some examples of primary prevention include:

- Organizational strategies: Organizational strategies may include defining workers roles and responsibilities clearly, matching workload with worker's capabilities and resources, redesigning job, matching work schedules with demands/ responsibilities outside the job, improving ergonomics and work/environmental design, improving communications between managers and workers, establishing career steps, offering equitable pay structures and compensation. 
Table 1: Possible psychosocial hazards prevention strategies

\begin{tabular}{|c|c|}
\hline Hazards & Possible prevention strategies \\
\hline Workload and workplace & $\begin{array}{l}\text { Improve own time management, improve workflow, ensure sufficient breaks and recreation time, } \\
\text { avoid unrealistic deadlines, substitute heavy manual tasks with machinery to reduce physical } \\
\text { workload, avoid encouraging employees to regularly work for long hours. }{ }^{[26,27]}\end{array}$ \\
\hline Working Environment & $\begin{array}{l}\text { Assess work environment in consultation with employees, ensure that there are effective systems } \\
\text { in place to identify and control risks }\end{array}$ \\
\hline Organizational culture and function & $\begin{array}{l}\text { Focus on clarity and objectives around work expectations, engaging of strong employees, good } \\
\text { co-worker relations, provision of development-oriented feedback, transparency and equity of } \\
\text { organizational processes and procedures }{ }^{[26]}\end{array}$ \\
\hline Interpersonal relationship at work & $\begin{array}{l}\text { Establish clear job descriptions and tasks assignments, supportive supervision, participative } \\
\text { decision-making, and prior-agreed mechanism to reduce conflict }{ }^{[26]}\end{array}$ \\
\hline Career development & $\begin{array}{l}\text { Consider using mobility, mentoring, and career counseling programs to fit individuals to jobs, develop } \\
\text { the capability and support in structuring career path, use team-based projects to broaden skills, and } \\
\text { develop responsibilities }{ }^{[26]}\end{array}$ \\
\hline Absenteeism & $\begin{array}{l}\text { Develop and implement absence management policy, train and provide managers with advice and } \\
\text { assistance in handling difficult absence issues }{ }^{[27]}\end{array}$ \\
\hline $\begin{array}{l}\text { Other employees' behavior (erratic } \\
\text { behavior, depression) }\end{array}$ & $\begin{array}{l}\text { Develop and implement an early intervention stress management policy, provide training in coping } \\
\text { skills and individual stress management, consider the need to improve work team climate and } \\
\text { supportive leadership }{ }^{[27]}\end{array}$ \\
\hline
\end{tabular}

- Individual strategies: Individual strategies may include lifestyle management, participation in workplace, improvement of quality, and management of time.

Secondary Intervention. Secondary interventions are aimed at improving individual's response to stressors. ${ }^{[21]}$ The approach seeks to prevent work-related stress by developing individual skills such as self-awareness in stress management through training or by providing individuals with a meditation or number of basic relaxation techniques. Stress education and stress management training serve as a useful function in helping individuals to recognize the symptoms of stress and to overcome much of the negativity and stigma associated with the stress level. ${ }^{[28]}$ In addition, individual-level activities are associated with health promotion and lifestyle modification programs such as good nutrition and physical activity, whereas organizational-level strategy focuses on team-building activities.

- Organizational strategies: Organizational strategies may include team-building, diversity programs, worker education, and training and access to fitness facilities/walking paths.

- Individual strategies: Individual strategies may include good nutrition, physical activity, meditation/relaxation techniques, social/emotional outlets, assertiveness training, coping classes, cognitive management therapy, and anger management.
Tertiary Intervention. Tertiary interventions are reactive and aimed at minimizing the effects of stress-related problems once they have already occurred. ${ }^{[21]}$ Reduction on the impact of work-related stress on worker's health can be done by developing appropriate rehabilitation and "return-to-work" systems and enhanced occupational health provisions. Interventions at the tertiary level typically involve the provision of counseling services for employee problems in the work or personal domain or therapy for people experiencing burnout or depression or rehabilitation measures for people who have been absent from their work for a long time due to illness. The employee assistance program such as return-to-work program, psychological counseling or therapy, traumatic event debriefing, medical care, and treatment and rehabilitation are associated with tertiary intervention.

- Monitor and Review: The final step includes setting up clear objectives as well as establishing targets and performance indicators. This is followed by monitoring and reviewing the effectiveness of the program. The outcome of each risk mitigating action should be reviewed to ensure that actions are effective and no hazards or risks are introduced by the actions taken. Some control measures should be maintained to ensure that measures are kept in working order. Eventually, findings have to be reviewed to inform refinements and improvements. Review 
can be done by looking in depth, collecting data, or by observing. After completion of one entire cycle of risk management, a new phase of assessment has to be scheduled to ensure that always the best actions are taken and new hazards are included into risk management. It should be kept in mind that the process needs to be followed by effective and constructive delivery of information and feedback.

Proper application of risk management approach at workplace environment aids to prevent and control the causes of psychosocial hazards, which finally will help to improve the overall health, well-being of the employees, and workplace culture. However, there are some issues about the risk assessment that need to be addressed while following risk management approach. There remains a debate on how impacts can be assessed and how hazards can harm the workplace environment. In addition, it is difficult to identify the concurrent roles of physical, psychological, and organizational factors to the occurrence of hazards that threaten health and safety and productivity of the organization. This difficulty suggests the need of more research studies to recognize the role of physical, psychosocial, and organizational factors that affect workers' health and safety of organizations as well as in identifying and publicizing case studies of best practices. ${ }^{[18]}$ Studies should focus on developing techniques that allow the proper assessment of risk.

Moreover, the role of policy can never be undermined and is highly essential for improving workplace environment. It is believed that any policy intended to improve the workplace not only helps to minimize negative aspects of work but also increases the positive aspects such as creating a greater sense of control and support among employees. On the contrary, most of the workplaces have no legislative provision to deal specifically with workplace stress or psychological harm. ${ }^{[29]}$ It is essential that, at the policy level, the concerned authorities should promote evidence-based policy development and legislation to assist the intervention of potential risk factors for psychosocial hazards and improve the psychosocial work environment. Moreover, research findings should include some forms of clear and practical guidance for risk-reduction interventions at workplace.

\section{Conclusion}

Psychosocial hazard at workplace is a large and growing public health problem, requiring an appropriate public health response. Given the high vulnerability of psychosocial hazards at workplace, a conscious effort is required for the protection and among the measures available, and using the systems and structured approach to risk management has proven to be the most effective strategy to address the challenges of modern work environment and to improve the health of employees. To further facilitate prevention and improve the psychosocial work environment, emphasis should be given to the development of an evidence-based policy and legislation. More research study is needed to overcome the shortcomings of risk management approach and to identify new strategies and solutions that are applicable to prevent and control hazards and risks at workplace.

\section{References}

1. World Health Organization. Constitution of the World Health Organization. Basic Documents, Forty-fifth edition, supplement. World Health Organization. 2006. Available at: http://www.who. int/governance/eb/who_constitution_en.pdf (last accessed on December 26, 2013).

2. Jain A, Saeed K, Arnaout S, Kortum E. The psychosocial environment at work: an assessment of the World Health Organization Regional Office for the Eastern Mediterranean. East Mediterr Health J 2012;18(4):325-31.

3. Briner R. Relationships between work environments, psychological environments and psychological well-being. J Occup Med 2000; 50(5):299-303.

4. Leka S, Jain A. Health Impact of Psychosocial Hazards at Work: An Overview. World Health Organization. 2010. Available at: http://whqlibdoc.who.int/publications/2010/9789241500272_eng. pdf (last accessed on December 27, 2013).

5. Dollard M, Bailey T, McLinton S, Richards P, McTernan W, Taylor A, et al. The Australian Workplace Barometer: Report on Psychosocial Safety Climate and Worker Health in Australia. Safe Work Australia. 2012. Available at: http://www.safeworkaustralia.gov.au/sites/swa/about/Publications/Documents/748/TheAustralian-Workplace-Barometer-report.pdf (last accessed on December 29, 2013).

6. World Health Organization. Healthy Workplaces: A Model for Action. World Health Organization. 2010. Available at: http://www. who.int/occupational_health/publications/healthy_workplaces_ model_action.pdf (last accessed on January 3, 2014).

7. Arjas $\bar{P}$, Luukkonen $R$, Riihimäki $H$. Work stress and risk of cardiovascular mortality: prospective cohort study of industrial employees. BMJ 2002;325(7377):1386.

8. Cosgrove MP, Sargeant LA, Caleyachetty R, Griffin SJ. Work-related stress and type 2 diabetes: systematic review and meta-analysis. Occup Med 2012;62(3):167-73.

9. Chopra P. Mental health and the workplace: issues for developing countries. Int J Ment Health Syst 2009;3(1):4.

10. Sullivan L. An Introduction to Comprehensive Workplace Health Promotion. The University of Toronto. 2004. Available at: http://www. thcu.ca/workplace/documents/intro_to_workplace_health_promotion v1.1.final.pdf (last accessed on January 5, 2014)

11. Institute of Work, Health, and Organization. Towards the Development of a European Framework for Psychosocial Risk Management at the Workplace. Institute of Work, Health and Organization, UK. 2008. Available at: http://ec.europa.eu/health/ mental_health/eu_compass/reports_studies/psychosocial_risk management_workplace.pdf (last accessed on January 7, 2014).

12. Blewett V, Shaw A, LaMontagne A, Dollard M. Job Stress Causes, Impact and Interventions in the Health and Community Sector. The University of South Australia. 2006. Available at: http://www.workcover.nsw.gov.au/formspublications/publications/ Documents/job_stress_causes_impact_interventions_health_community_sector_report_november_2006_5007.pdf (last accessed on January 7,2014$)$. 
13. Brun J, Lamarche C. Assessing the Costs of Work Stress [research report]. Université Laval. 2006. Available at: http://www.cgsst.com/ stock/eng/doc272-806.pdf (last accessed on January 8, 2014).

14. Noor S. Examining the relationship between work life conflict, stress and turnover intentions among marketing executives in Pakistan. Int J Bus Manag 2008;3(11):93-102.

15. Hoel H, Sparks K, Cooper C. The Cost of Violence/Stress at Work and the Benefits of a Violence/Stress Free Working Environment Geneva: International Labor Organization (ILO) 2001.

16. Lundqvist D. Psychosocial Work Conditions, Health, and Leadership of Managers. Linköping. 2013. Available at: http://www. diva-portal.org/smash/get/diva2:643342/fulltext01.pdf (last accessed on January 8, 2014).

17. Canadian Center for Occupational Health and Safety. Mental Health at Work [Online]. Available at: http://www.ccohs.ca/ oshanswers/psychosocial/mentalhealth_work.html (last accessed on January 9, 2014).

18. European Agency for Safety and Health at Work. Priorities for Occupational Safety and Health Research in the EU-25. 2005. Available at: https://osha.europa.eu/en/publications/reports/6805648 (last accessed on January 9, 2014).

19. Punnett L, Cherniack M, Henning R, Morse T, Faghri P. A conceptual framework for integrating workplace health promotion and occupational ergonomics programs. Public Health Rep 2009;124(9):16-25.

20. van der Molen HF, Lehtola MM, Lappalainen J, Hoonakker PL, Hsiao H, Haslam R. Interventions to prevent injuries in construction workers. Cochrane Database Syst Rev 2012;12(6):CD006251.

21. LaMontagne A, Keegel T, Louie AM, Ostry A, Landsbergis PA. A comprehensive review of the job stress intervention evaluation literature: assessing the evidence of effectiveness for systems approach. Int J Occup Environ Health 2007;13(12):268-80.

22. Cox T, Griffiths A. Work-Related Stress in Nursing: Controlling the Risk to Health. International Labor Office, Geneva. 1996. Available at: http://www.mtpinnacle.com/pdfs/Work-relatedstressin nursing.pdf (last accessed on January 12, 2014).
23. Morag I, Luria G. A framework for performing workplace hazard and risk analysis: a participative ergonomics approach. J Ergon 2013;56(7):1086-1100.

24. Safe Work Australia. How to Manage Work Health and Safety Risks: Code of Practice. Safe Work Australia publications. 2011. Available at: http://www.safeworkaustralia.gov.au/sites/SWA/about/ Publications/Documents/633/How_to_Manage_Work_Health_ and_Safety_Risks.pdf (last accessed on January 12, 2014).

25. Rick J, Briner R. Psychosocial risk assessment: problems and prospects. Occup Med 2000;50(5):310-14.

26. Australian Government Comcare. Working Well: An Organisational Approach to Preventing Psychological Injury. Comcare. 2008. Available at: http://www.comcare.gov.au/forms_and_publications/ publications/safety_and_prevention/?a=41369 (last accessed on January 14, 2014).

27. European Agency for Safety and Health at Work (EU-OSHA) Managing Psychosocial Risks with Cleaning Workers [Online]. Available at: https://osha.europa.eu/en/publications/e-facts/efact (last accessed on January 15, 2014).

28. Cooper CL, Cartwright $\mathrm{S}$. An intervention strategy for workplace stress. J Psychosom Res 1997;43(1):7-16.

29. Houtman I, Jettinghoff K. Raising Awareness of Stress at Work in Developing Countries: A Modern Hazard in a Traditional Working Environment: Advice to Employers and Worker Representatives. Protecting Workers' Health Series. 2007. Available at: http:// www.who.int/occupational_health/publications/raisingawarenessof stress.pdf (last accessed on January 13, 2014).

How to cite this article: Gyawali B. Effective approaches to improve the psychosocial work environment. Int J Med Sci Public Health 2015;4:1-6

Source of Support: Nil, Conflict of Interest: None declared. 